\title{
Prototype Smart Home Menggunakan Modul Wifi ESP8266 Dengan Aplikasi Telegram
}

\author{
Nisa Gracella Aslamia Oktari ${ }^{1}$, Ali Nurdin ${ }^{2}$, Abdul Rakhman ${ }^{3}$ \\ Program Studi Teknik Telekomunikasi, Politeknik Negeri Sriwijaya \\ Jl. Srijaya Negara Bukit Besar, Palembang \\ nisacella2@gmail.com, aalinurdin67@gmail.com,arahmanhamid.60@gmail.com
}

\begin{abstract}
Smart Home is a technology that can make it easier for users to manage comfort and safety at home so they can control the equipment used, homeowners can open the gate automatically and check the temperature and humidity of the existing room at home. Sometimes homeowners forget to turn off or turn on the equipment used, and forget to close the gate again when no one is at home. From the above problems made a tool that can be used as a remote home appliance controller or can also be called smart home. This tool uses the ESP8266 wifi module as the main device and sensor control that is connected to the Telegram Application to give commands to the ESP8266 wifi module so that it can control the equipment used and is at home.
\end{abstract}

Keywords: ESP8266 Module, Telegram Messenger, Smart Home, DHT11

Abstrak

Smart Home merupakan teknologi yang dapat memudahkan pengguna untuk mengatur kenyamanan dan keamanan dirumah sehingga dapat mengontrol peralatan yang digunakan, pemilik rumah dapat membuka pintu pagar secara otomatis dan mengecek keadaan suhu dan kelembapan ruangan yang ada dirumah. Terkadang pemilik rumah lupa untuk mematikan atau menghidupkan peralatan yang digunakan, serta lupa menutup kembali pintu pagar saat sedang tidak ada orang dirumah. Dari permasalahan diatas dibuatlah alat yang dapat digunakan sebagai pengontrol peralatan rumah jarak jauh atau dapat disebut juga smart home. Alat ini menggunakan modul wifi ESP8266 sebagai perangkat utama dan kendali sensor yang dihubungkan ke Aplikasi Telegram untuk memberikan perintah kepada modul wifi ESP8266 agar dapat mengendalikan peralatan yang digunakan dan ada dirumah.

Kata Kunci : Modul ESP8266, Telegram Messenger, Smart Home, DHT11

\section{PENDAHULUAN}

Teknologi yang dipakai saat ini berkembang sangat cepat untuk kehidupan, salah satunya yaitu jaringan internet. Saat ini Internet dibutuhkan sekali bagi banyak orang karena mempunyai banyak manfaat yang diperlukan untuk seharihari atau biasa disebut dengan Internet of Things (IoT). Teknologi Internet of Things (IoT) akan membuat sebuah rumah konvensional menjadi Smart Home, secara efektif semua device saling terhubung dengan device yang lain. Perangkat elektronik mengalami perkembangan menjadi lebih baik untuk bekerja sesuai dengan kebutuhan manusia [1].

Teknologi jaringan internet dapat digunakan untuk mengontrol peralatan rumah dari jarak jauh, sehingga memudahkan pemilik rumah untuk mengetahui peralatan yang digunakan masih menyala atau sudah dimatikan. Saat ini semakin banyak peralatan, baik peralatan rumah tangga maupun peralatan perkantoran yang menggunakan tenaga listrik. Hal ini di satu sisi sangat membantu dan memudahkan, di sisi lain membuat beban listrik semakin bertambah. Sehingga 
bisa dibilang penggunaan listrik semakin boros. Terlebih lagi jika ada pengguna yang lupa mematikan peralatan listrik. Lampu listrik menjadi salah satu penyumbang terbesar penggunaan tenaga listrik[2]. Dengan adanya alat ini pemilik rumah tidak perlu khawatir jika lupa mematikan peralatan elektronik yang digunakan.

Aplikasi chatting saat ini berkembang sangat pesat seolah sudah menjadi kebutuhan pokok bagi masyarakat modern. Dengan adanya smartphone keberadaan aplikasi chatting saling berkaitan dan memiliki manfaat yang beragam bagi berbagai aspek kehidupan manusia, selain untuk berkomunikasi, menjalankan bisnis, media untuk berbagi foto, bisa juga digunakan sebagai alat pengontrol keadaan rumah dan sebagainya. Salah satu aplikasi chatting yang banyak digunakan yaitu, Telegram, merupakan salah satu aplikasi chatting yang cukup populer layaknya WhatsApp, Line, dan lain-lain [3]. Perbedaan Telegram dengan aplikasi chatting lainnya yaitu, selain sebagai aplikasi chatting, Telegram juga menyediakan sebuah Application Progaramming Interface (API) yang diberi nama Bot API [4][5]. Bot API sendiri merupakan sebuah virtual robot yang didesain untuk menghandle pesan yang dikirim oleh pengguna maupun orang lain secara otomatis. Dengan Bot API ini pengguna dapat berinteraksi dengan bot yang mereka buat melalui chat dengan request, dan bot akan merespon tersebut sesuai dengan format yang telah diatur sebelumnya. Bot API ini, sangat dimudahkan untuk membuat berbagai macam project unik, mulai dari smart home, robotic dan sebagainya [6].

Penelitian tentang smart home sendiri telah banyak dilakukan diantaranya pada penelitian yang membahas tentang alat kendali listrik menggunakan Wemos D1 Mini. Dan penelitian lain mencoba membuat system kendali dengan media SMS, meskipun sudah bisa mengatasi jarak yang cukup jauh, teknologi SMS saat ini sudah jarang digunakan kebanyakan orang [3]. Penelitian yang lain juga ada yang menggunakan aplikasi telegram tetapi hanya untuk menghidup dan mematikan lampu saja, pada tugas akhir yang saya buat, selain untuk menghidupkan dan mematikan peralatan elektronik seperti lampu, kipas, dan membuka pintu, disini saya menggunakan motor servo untuk membuka pintu dan sensor suhu untuk mengukur suhu ruangan secara otomatis yang akan ditampilkan pada telegram chatting.

\section{METODOLOGI PENELITIAN}

\subsection{Perancangan Perangkat}

Pada penelitian ini perancangan alat dibagi menjadi dua bagian, yaitu perancangan perangkat keras (hardware), dan perancangan perangkat lunak (software). Perancangan alat diawali dengan perancangan blok diagram secara keseluruhan. Dari blok diagram tersebut merupakan salah satu bagian terpenting dalam suatu perancangan alat, karena dari blok diaram inilah dapat diketahui cara kerja rangkaian secara keseluruhan. 


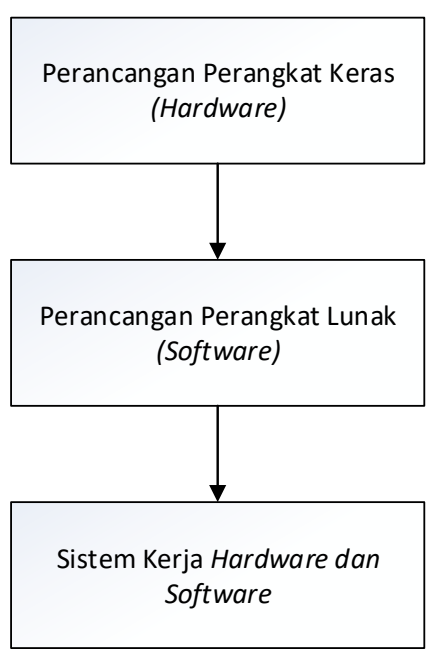

Gambar 1. Tahap Penelitian

\subsection{Perancangan Perangkat Keras (Hardware)}

Perancangan perangkat keras (hardware) merupakan perancangan alat yang akan dibuat. Komponen yang digunakan seharusnya memiliki karakteristik yang sesuai dengan kebutuhan pembuatan alat. Perancangan perangkat keras diawali dengan membuat blok diagram.

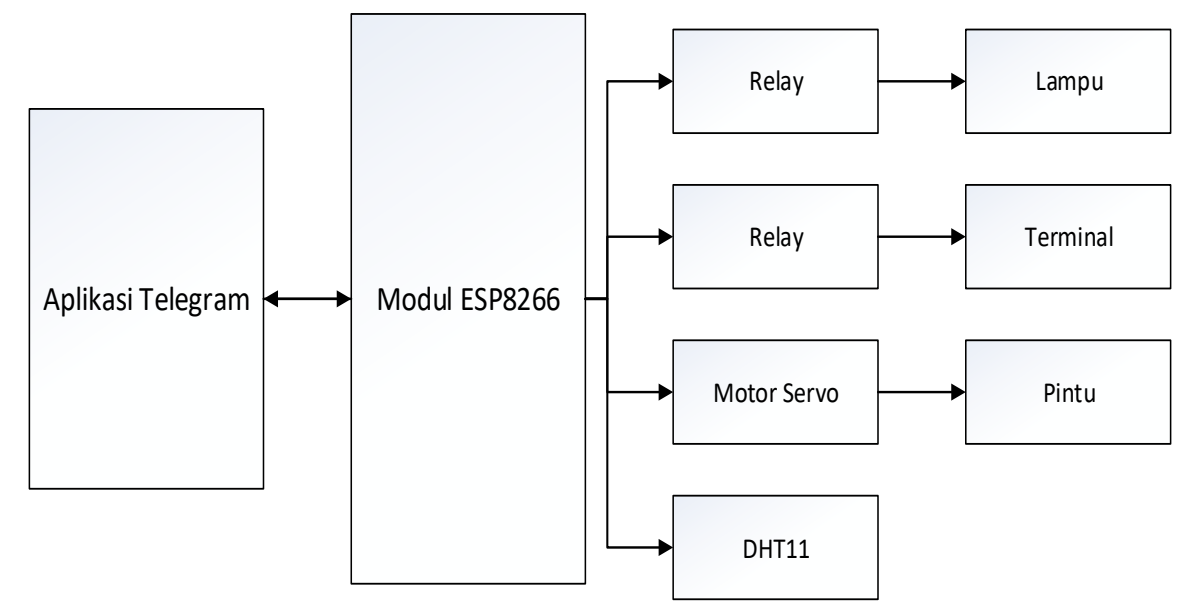

Gambar 2. Blok Diagram Perangkat Keras (Hardware)

Pada gambar 2 diatas perangkat keras yang digunakan terdapat modul ESP8266 yang berfungsi sebagai pengelola dan pengirim perintah sehingga tidak diperlukan lagi mikrokontroler yang lain dan berfungsi untuk menentukan arah putaran motor dc untuk membuka dan mengunci pintu, dan juga relay sebagai saklar digital untuk mematikan dan menghidupkan lampu dan kipas.

\subsection{Perancangan Perangkat Lunak (Software)}

Setelah tahap perancangan perangkat keras (hardware), tentunya tidak terlepas dari perancangan perangkat lunak (software) yang ditunjukkan pada gambar 3 mulai dari menetikan printah /Start jika berhasil telegram akan 
Jurnal Riset Sistem Informasi Dan Teknik Informatika (JURASIK)

Volume 5 Nomor 2 Agustus, pp 258-265

ISSN: 2527-5771/EISSN: 2549-7839

https://tunasbangsa.ac.id/ejurnal/index.php/jurasik

menampilka pilihan button, jika tidak muncul periksa lagi apakah modul ESP8266 tersambung ke wifi yang digunakan. Setelah pilihan button muncul dapat memilih apa yang ingin dikendalikan atau yang ingin dihidupkan. Setelah mengirimkan printah untuk mengontrol, otomatis akan mendapatkan pesan balasan bahwa perintah terbaca pada telegram.

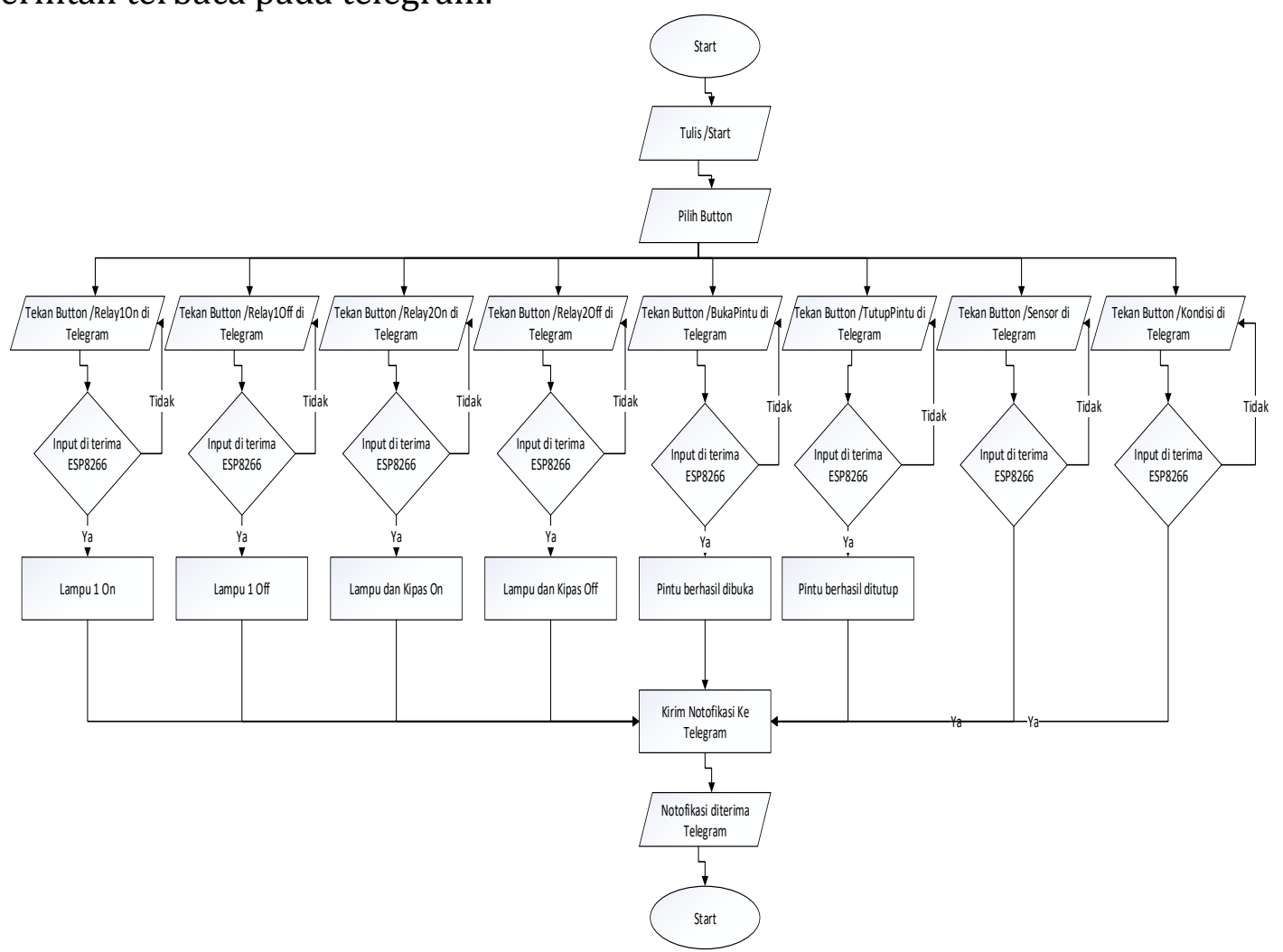

Gambar 3. Blok Diagram Perangkat Lunak (Software)

Pada gambar 3 ditunjukan bagainama membuat bot telegram untuk menyambungkan ESP8266 dengan aplikasi telegram messanger.

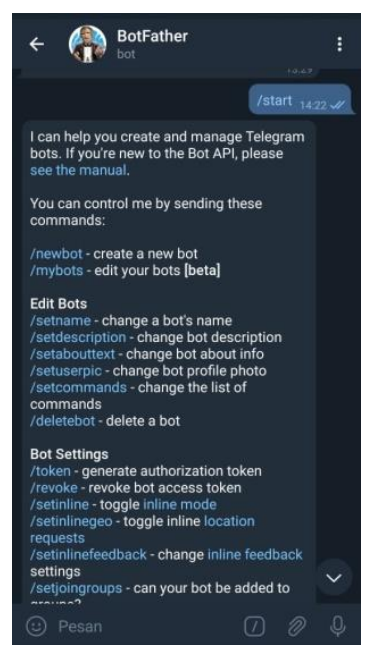

Gambar 4. Tampilan Pembuatan Bot pada Telegram Messanger 
Jurnal Riset Sistem Informasi Dan Teknik Informatika (JURASIK)

Volume 5 Nomor 2 Agustus, pp 258-265

ISSN: 2527-5771/EISSN: 2549-7839

https://tunasbangsa.ac.id/ejurnal/index.php/jurasik

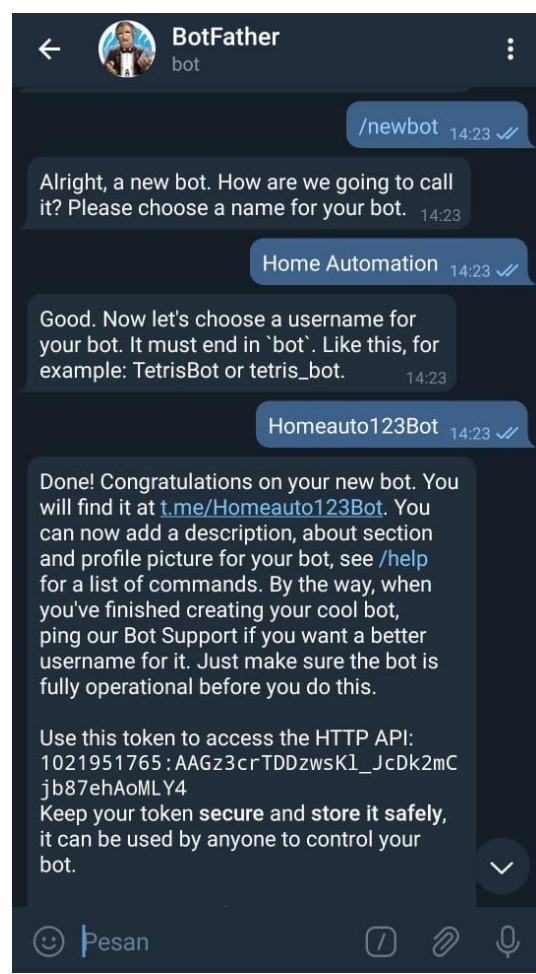

Gambar 5. Tampilan Pembuatan Bot pada Telegram Messanger

Setelah mendapatkan token pada aplikasi telegram, token tersebut dapat dimasukan pada program seperti yang ditunjukkan pada gambar 5 dibawah ini:

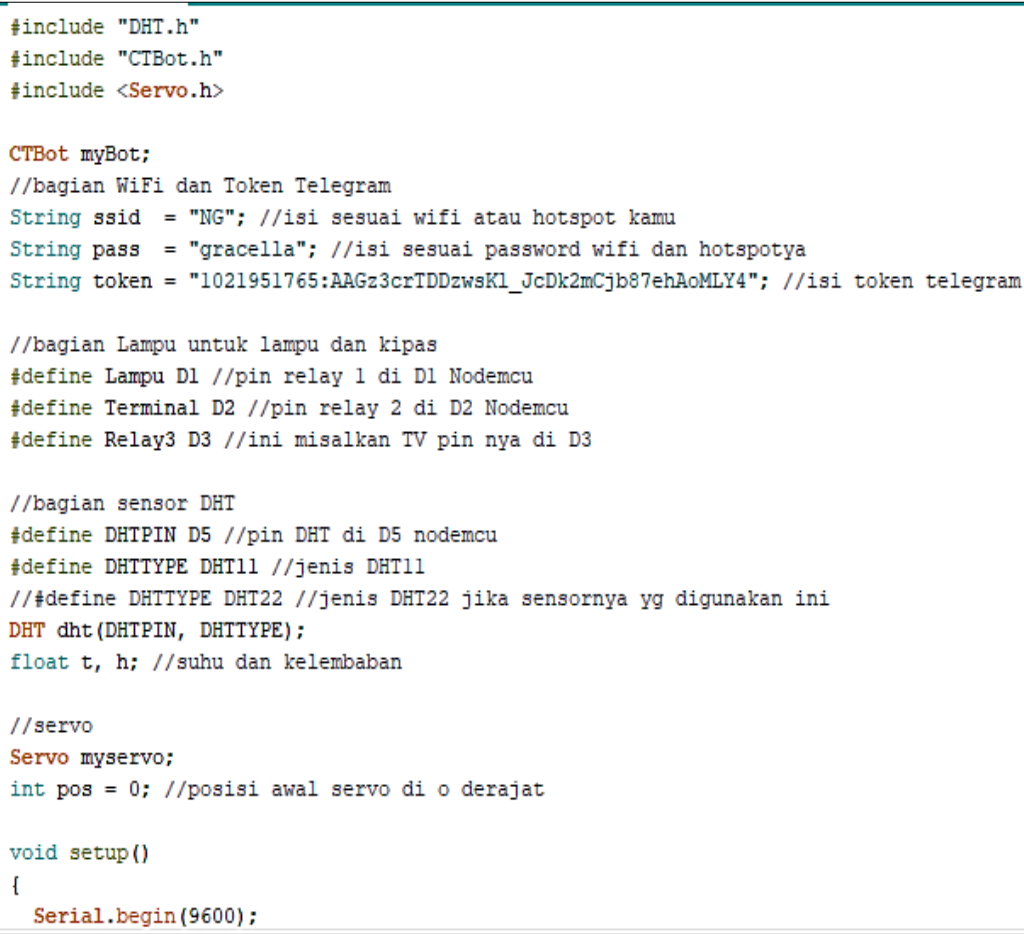

Gambar 6. Tampilan Coding ESP8266 


\section{HASIL DAN PEMBAHASAN}

\subsection{Hasil Perancangan Hardware}

Pada rancangan smarthome menggunakan aplikasi telegram ini menggunakan relay dua channel, motor servo, dan sensor dht11 yang akan dihubungkan ke modul ESP8266. Pengujian ini dilakukan unuk mengetahui apakah system bekerja atau tidak.

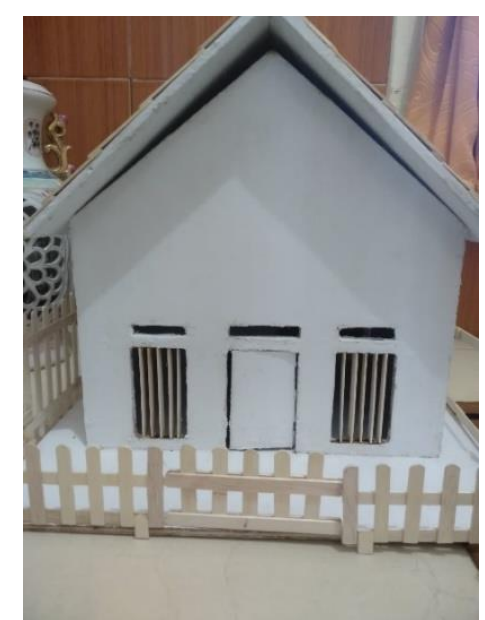

Gambar 7. Tampilan Prototype

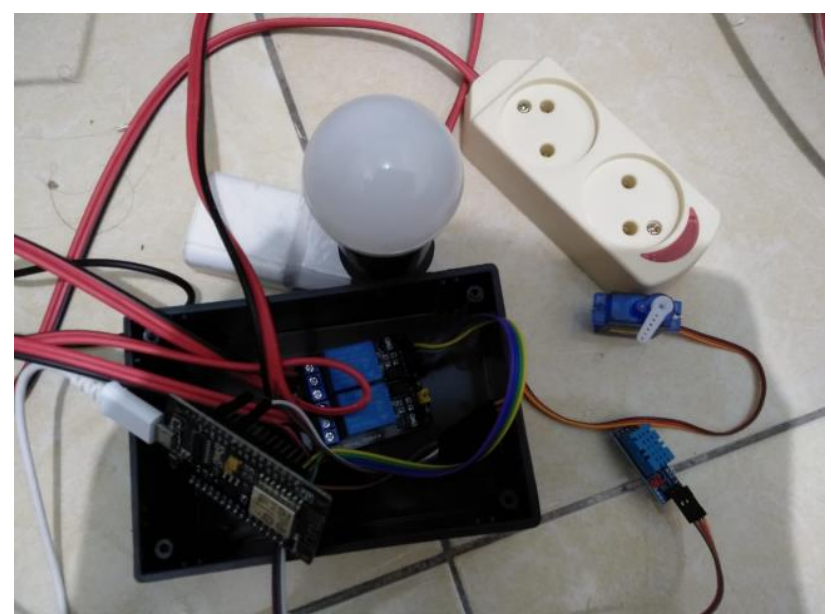

Gambar 8. Komponen pada Box

\subsection{Tampilan Pada Perangkat Lunak (Software)}

Bentuk tampilan jika pengujian pada aplikasi telegram berhasil. Maka aplikasi telegram messenger akan mengirimkan pesan balasan melalui jaringan internet. Ditunjukkan pada gambar 9 dibawah ini :

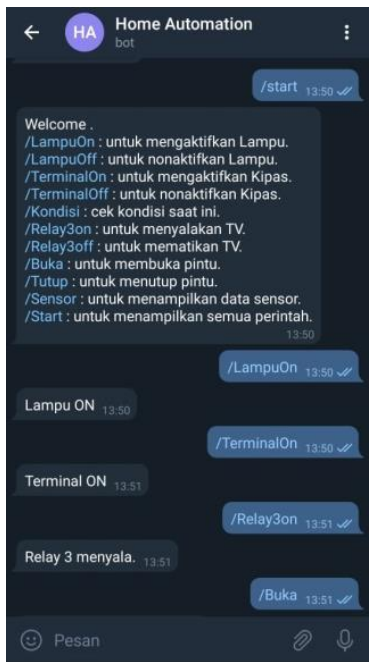

Gambar 9. Tampilan pada Bot Telegram Messanger

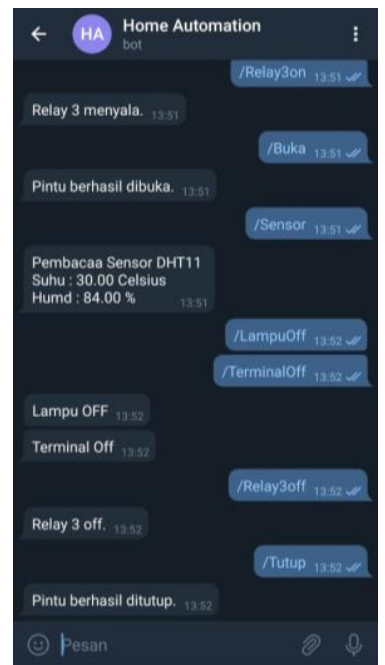

Gambar 10. Tampilan pada Bot Telegram Messanger 
Perintah/Start pada pesan yang dikirim ke module ESP8266, akan menampilkan pilihan button yang akan digunakan. Perintah yang dapat dikirimkan untuk menghidupkan lampu. Perintah /LampuOn akan membuat lampu menyala secara otomatis dan perintah untuk mematikan lampu menggunakan /LampuOff. Untuk menghidupkan terminal menggunakan perintah/TerminalOn dan untuk mematikan menggunakan perintah/TerminalOff. Perintah untuk membuka pintu yaitu/Buka dan untuk menutup menggunakan perintah /Tutup. Dan untuk mengetahui suhu dan kelembapan ruangan sekitar menggunakan perintah /Sensor dan akan muncul notifikasi berapa suhu dan kelembapan pada ruangan tersebut.

\subsection{Tabel Hasil Pengujian}

Pada table dibawah ini menunjukkan hasil dari penujian 2 buah relay, sensor dht11 dan motor servo yang telah dirancang. Hasil pengujian berhasil yaitu relay 1 dan 2, sensor dht11 dan motor servo dapat dikontrol oleh aplikasi telegram messanger.

Tabel 1. Pengujian Pada Hardware

\begin{tabular}{|c|c|c|c|}
\hline Pengujian & Komponen & Bekerja & Tidak Bekerja \\
\hline 1 & Relay 2 Channel & $\sqrt{ }$ & \\
\hline 2 & Sensor DHT11 & $\sqrt{ }$ & \\
\hline 3 & Motor Servo & $\sqrt{ }$ & \\
\hline 4 & ESP8266 & $\sqrt{ }$ & \\
\hline
\end{tabular}

Tabel 2. Pengujian Pada Aplikasi Telegram Messanger

\begin{tabular}{|c|c|c|c|}
\hline Pengujian & $\begin{array}{c}\text { Perintah pada } \\
\text { Telegram }\end{array}$ & Berhasil & Tidak Berhasil \\
\hline 1 & /LampuOn & $\sqrt{ }$ & \\
\hline 2 & /LampuOff & $\sqrt{ }$ & \\
\hline 3 & /TerminalOn & $\sqrt{ }$ & \\
\hline 4 & /TerminalOff & $\sqrt{ }$ & \\
\hline 5 & /Kondisi & $\sqrt{ }$ & \\
\hline 6 & /Buka & $\sqrt{ }$ & \\
\hline 7 & /Tutup & $\sqrt{ }$ & \\
\hline 8 & /Sensor & $\sqrt{ }$ & \\
\hline 9 & /Start & $\sqrt{ }$ & \\
\hline
\end{tabular}

\section{SIMPULAN}

Dari hasil pembahasan dan perancangan alat mengenai Smart home menggunakan ESP8266 dengan menggunakan aplikasi telegram messanger dapat disimpulkan bahwa kinerja hardware dan software bekerja sesuai dengan kinerjanya. Komponen yag digunakan bekerja dengan baik and sesuai fungsinya, dimana relay bekerja sebagai switch untuk menghidupkan terminal dan lampu, sedangkan motor servo berfungsi untuk membuka dan menutup pintu secara otomatis dan sensor dht11 berfungsi untuk mengetahui suhu dan kelembapan pada daerah rumah. Respon dari telegramnya bekerja dengan baik dan sesuai 
Jurnal Riset Sistem Informasi Dan Teknik Informatika (JURASIK)

Volume 5 Nomor 2 Agustus, pp 258-265

ISSN: 2527-5771/EISSN: 2549-7839

https://tunasbangsa.ac.id/ejurnal/index.php/jurasik

dengan perintah yang dikirimkan. Dengan adanya alat ini pemilik rumah tidak perlu merasa khawatir saat lupa mematikan barang elektronik yang sedang dipakai dirumah.

\section{DAFTAR PUSTAKA}

[1] Peby Wahyu Purnawan., Yuni Rosita, "Rancang Bangun Smart Home system menggunakan NodeMCU ESP8266 Berbasis Komunikasi Telegram Messenger" Techno.COM, Vol. 18, No. 4, November 2019.

[2] Ihsan Kamil Teja Sumarna., Satrio Nugroho., Aldi Suryanto., Dolly Virgian Shaka Yudha Sakti., "Rancang Bangun Kendali Lampu Menggunakan Wemos D1 Mini Dengan Pusat Kendali Media Sosial Telegram." Ilmu Komputer Unila Publishing Network, Vol 7 No. 2 , Oktober 2019.

[3] Jurnaldo Ambarita1., Dr. Rizki Ardianto P., S.T., M.T., Agung Surya Wibowo, S.T., M.T., "Rancang Bangun Prototipe Smarthome Berbasis Internet Og Things Menggunakan Aplikasi Blynk Dengan Module Esp8266.” Universitas Telkom S1 Teknik Elektro, No Katalog 19.04.1953, Bandung, 2019.

[4] Sumenge., 2014. Perancangan Kendali Lampu Berbasis Android. Jurnal Teknik Elektro dan Komputer. Vol 3, No. 2, April 2014.

[5] Sutono., 2010. Perancangan Sistem Aplikasi Otomatisasi Lampu Penerangan Menggunakan Sensor Gerak Dan Sensor Cahaya Berbasis Arduino Uno. Jurnal UNIKOM. Vol 12, No. 2, Januari 2015.

[6] Wirdasari, Dian., 2010. Membuat Program Dengan Menggunakan Bahasa C. Jurnal SAINTIKOM. Vol 8, No. 1, Januari 2010. 